Sexual dysfunction

\section{Sexual dysfunction in women with HIV} D Goldmeier, A Kocsis, M Wasserman

\section{Not discussing sexual problems in women with HIV is all too easily done}

$\mathrm{B}$ y the end of 2003 it was estimated that 37 million adults were infected with HIV, of whom 27 million resided in sub-Saharan Africa. ${ }^{1}$ Twice as many women are infected as men. ${ }^{2}$ Untreated, they will inevitably fall sick and die. However, in the earlier stages of the disease and in those with access to combination antiretroviral chemotherapy, quality of life issues such as sexual functioning and sexual satisfaction are important.

What is known about sexual dysfunction in women with HIV? The answer is probably very little.

The National Sexual Attitudes and Lifestyles Survey (2000) in the United Kingdom, which surveyed 11161 of the general population between the ages of 16-44, found that $54 \%$ of women with one or more current sexual partners had at least one sexual problem for a month over the previous year and that $16 \%$ complained of such problems for 6 months or more. ${ }^{3}$ Female sexual dysfunction in the general population thus appears to be common. It may be caused by medical problems such as diabetes, hypertension, or lowered oestrogen levels at the menopause. However, women's sexual pleasure is commonly contextually related, so that a quarter of the general female population admit to marked distress about their sexual relationship and their sexuality. ${ }^{4}$ The best predictors of sexual distress seem to be markers of general emotional wellbeing and the emotional relationship with their partner. Also important are psychosocial and economic issues-for instance, doing a full time job as well as looking after children may lead to exhaustion and hence low sexual desire in a woman.

However, data on sexual dysfunction in HIV positive women are harder to come by and what studies there are come from small convenience based samples. $^{56}$

Specific causes of sexual dysfunction in HIV positive women may be broadly categorised under medical and psychosocial headings. Medical causes include low sexual desire secondary to the malaise of advanced HIV disease, endocrinopathies, and autonomic and peripheral neuropathies, particularly in women on combination antiretroviral therapy..$^{7-9}$ Psychosocial causes include grief reactions after developing HIV, anxiety, and depression. ${ }^{10}$ Lipodystrophy may identify and stigmatise patients with HIV on treatment to others and may result in sexual and personal ostracisation and isolation. ${ }^{11} 12$

In this issue of STI ( $p$ 333) Lambert and colleagues report on sexual practices and difficulties in a group of 82 ments and the community in the United Kingdom. Three quarters of them were black Africans. Lambert et al found a high level of dysfunction and dissatisfaction in this sample. The paper has a number of drawbacks - the major ones being its small size and biased uncontrolled sample. However, its major merit is that it raises important issues.

Sexual dysfunction in women with HIV is a complex subject, not least because the contextual non-medical issues are manifold. So for African women in the United Kingdom these may include ongoing application for political asylum, work permits and citizenship, housing and financial problems, as well as depression and grief reactions. It would be surprising if these issues did not affect libido and sexual pleasure.

So much for the United Kingdom. What of women who have HIV in subSaharan Africa? Personal experience (MW) and anthropological studies in South Africa $^{13}$ suggest there is widespread male coercion and violence in sexual relationships. Some contextual issues in South Africa, such as poverty, are not dissimilar to those in the United Kingdom. However, others, such as lack of access to treatment (new legislation recently passed makes treatment available to everyone, yet roll out of this policy will take time), fear of disclosure of HIV status (which is known to result in violence, job loss, homelessness, and even murder) are dissimilar. Furthermore, sex and sexual problems may not be openly discussed in some South African communities. Again, it would be surprising in these scenarios if sexual women from hospital outpatient depart- dysfunction, in particular low desire, was not a result.

Since sexual functioning may offer a window into physiological abnormality as well as onto psychosocial difficulties of a woman, it is good clinical practice to assess these aspects of her functioning routinely. Not discussing sexual problems in women with HIV is all too easily done. Assuming that any difficulties are caused by physical problems rather than psychosocial or contextual issues does not encourage a holistic approach to the treatment of HIV and decreases the quality of life in these women who are already markedly disadvantaged.

Sex Transm Infect 2005;81:284. doi: $10.1136 /$ sti. 2004.009266

Authors' affiliations

D Goldmeier, A Kocsis, St Mary's Hospital, London, UK

M Wasserman, Cape Town, South Africa

Correspondence to: Dr David Goldmeier, Jane Wadsworth Sexual Function Clinic, Jefferiss Wing, St Mary's Hospital, Praed Street, London W2 1NY, UK; david.goldmeier@st-marys.nhs. uk

\section{REFERENCES}

1 Worldwide HIV and AIDS epidemic statistics information 2003. www.avert.org/ worlstatinfo.htm.

2 UNICEF. Gender equality-the situation of women and girls: facts and figures. www.unicef.org/ gender/index factandfigures. hyml.

3 Mercer CH, Fenton KA, Johnson AM, et al. Sexual function problems and health seeking behaviour in Britain: national probability sample survey. BMJ 2003;327:426-7.

4 Bancroft J, Loftus J, Scott Long J. Distress about sex. A national survey of women in heterosexual relationships. Arch Sex Behav 2003;32:193-208

5 Bova C, Durante A. Sexual functioning among HIV-infected women. AIDS Patient Care STDs 2003; 17:75-83

6 Goggin K, Engelson ES, Rabkin JG, et al. The relationship of mood, endocrine and sexual disorders in human immunodeficiency virus positive $(\mathrm{HIV}+)$ women: an explanatory study. Psychosomatic Medicine 1998;60:1 1-16.

7 Huang JS, Wilke SJ, Dolan S, et al. Reduced testosterone levels in human immunodeficiency infected women with weight loss and low weight. Clin Infect Dis 2003:36:499-506.

8 Gluck T, Degenhardt E, Scholmerich J, et al. Autonomic neuropathy in patients with HIV: course, impact of disease stage and medication. Clin Auton Res 2000;10:17-22.

9 Lopez OL, Becker JT, Dew MA, et al. Risk modifiers in peripheral sensory neuropathy in HIV infections/ AIDS. Eur J Neurol 2004;1 1:97-102.

10 Olley BO, Gxamsa F, Seedat S, et al. Psychopathology and coping in recently diagnosed HIV/AIDS patients - the role of gender. S Afr Med J 2003;93:928-931.

gender. S Afr Med J 2003;93:928-931.
Tien DC, Cole SR, Williams CM, et al. Incidence of lipoatrophy and lipohypertrophy in the women's interagency HIV study. J Aquir Immun Def Syndr 2003;34:461-6.

12 Power R, Tate HL, McGill SM, et al. A qualitative study of the psychosocial implications of lipodystrophy syndrome on HIV positive individuals. Sex Transm Infect 2003;79:137-41.

13 Wood K, Jewkes R. Violence, rape and sexual coercion-everyday love in a South African township. Gend Rev 1997;5:41-6. 